\section{Psychosis, victimisation and childhood disadvantage}

\author{
Evidence from the second British National Survey \\ of Psychiatric Morbidity
}

\author{
PAUL E. BEBBINGTON, DINESH BHUGRA, TRAOLACH BRUGHA, \\ NICOLA SINGLETON, MICHAEL FARRELL, RACHEL JENKINS, GLYN LEWIS \\ and HOWARD MELTZER
}

\author{
Background Adverse early \\ circumstances may be more common in \\ people who later develop psychotic \\ disorders.
}

\begin{abstract}
Aims To use data from the second British National Survey of Psychiatric Morbidity to examine associations between psychotic disorders and a number of early victimisation experiences.
\end{abstract}

\begin{abstract}
Method Psychiatric disorders were identified through structured assessment of adults resident in private households in Britain $(n=8580)$. Respondents were asked whether they had experienced selected events displayed on cards.
\end{abstract}

Results Compared with respondents with other psychiatric disorders or with none, the prevalence of every experience bar one was significantly elevated in those with definite or probable psychosis. The largest odds ratio was for sexual abuse. Controlling for depressed mood somewhat reduced the odds ratios for the individual experiences.

Conclusions In people with psychosis, there is a marked excess of victimising experiences, many of which will have occurred during childhood. This is suggestive of a social contribution to aetiology.

Declaration of interest None.
Evidence of candidate causes from genetic, physical environmental and social environmental domains has encouraged the application of a biopsychosocial model to schizophrenia and other psychoses. Garety et al (2001) have suggested that early events may predispose to adult styles of thinking that foster the emergence of psychotic symptoms, particularly if some later event recapitulates aspects of the early events. This led us, in the current study, to use data from the second British National Survey of Psychiatric Morbidity (Singleton et al, 2001) to test the association of psychotic disorder with selected types of events. Most can be described as 'victimisation experiences' (see Table 1). They seem likely to involve the quality of intrusiveness, which Harris (1987) has postulated as having a particular relevance for psychotic disorders. Our hypothesis was that such events contribute to vulnerability to psychosis, and we therefore predicted that people with psychosis would report victimisation experiences over their lifetime more frequently than a normal control group. We also predicted that there would be no evidence of specificity, that is the same would be true of other types of psychiatric disorder.

\section{METHOD}

The second British National Survey of Psychiatric Morbidity, which took place between March and September 2000, investigated a sample of adults aged 16-74 years living in private households in England, Wales and Scotland (including the Highlands and Islands). The survey adopted a two-phase approach to the assessment of mental disorders. The firstphase interviews were carried out by staff from the Office for National Statistics (ONS), and included structured assessment of some mental conditions, together with screening instruments to assist the identification of other disorders during the second phase. The interviews also covered a range of other topics, such as service use, risk factors for disorder and socio-demographic factors. A subsample of people was then selected for a second phase consisting of clinical interviews that allowed a definite identification of psychosis. These interviews were conducted by seven specially trained psychologists employed by the University of Leicester, who had attended a training course in the administration of the Schedule for Assessment in Neuropsychiatry (SCAN; World Health Organization, 1999), followed by supervised clinical interviewing (Brugha et al, 1999). They were monitored throughout the field period of the survey to enhance standardisation. More details of the topics covered and the methods used are given by Singleton et al (2001).

\section{Sample}

The Royal Mail's small-users Postcode Address File was used as the sampling frame for the survey because of its good coverage of private households in Great Britain. The postcode sectors were stratified within each National Health Service region on the basis of socio-economic profile. Initially, 438 postal sectors (the primary sampling units) were selected with a probability proportional to size (i.e. the number of delivery points). Postal sectors contain on average 2550 delivery points; 36 were selected from each sector (with the exception of one sector that was accidentally sampled twice), yielding a sample of 15804 delivery points. These were visited to identify private households with at least one person aged 16-74 years. The Kish grid method was used to select systematically one person in each household (Kish, 1965).

Each interviewer was given 36 addresses to visit within a month. Letters were sent in advance to all addresses, giving information about the survey and advising the residents that an interviewer would be calling to tell them more about the survey and ask whether they would be willing to participate.

The selected adult in each household was asked to take part in an initial computer-assisted personal interview with an ONS interviewer. Questions about alcohol and drug dependence were answered by respondents themselves directly on the computer. All respondents who completed an initial interview were asked whether they would be willing to 
take part in a second phase. The secondphase sample was chosen to include:

(a) all respondents who satisfied one or more of the screening criteria for psychotic disorder;

(b) half of those who screened positive for antisocial and borderline personality disorder, but showed no evidence of psychotic disorder;

(c) 1 in 14 of the remainder.

Only those who agreed to being contacted for a second interview were included in the second phase.

\section{Coverage of disorders}

To test the first of our predictions, we compared individuals with a psychotic disorder with respondents who had no disorder. To test the specificity hypothesis, we used as comparison groups of people with non-psychotic mental disorders and those with drug or alcohol dependence. All diagnostic categories of mental disorder included in this paper were based on the ICD-10 (World Health Organization, 1992). In order not to prejudice the results, the diagnostic groups were established nonhierarchically: that is, individuals were sometimes members of more than one diagnostic group. The comparison group comprised respondents who fell into none of the chosen categories.

\section{Alcohol dependence}

Alcohol dependence was assessed using the Severity of Alcohol Dependence Questionnaire (SADQ; Stockwell et al, 1983). This consists of 20 questions covering symptoms of dependence, and possible scores range from 0 to 3 on each question. Adding up the scores from all questions gives a total SADQ score between 0 and 60 , indicating different levels of alcohol dependence. A score of 3 or less indicates no dependence, mild dependence is indicated by a score of 4-19, moderate dependence by a score of 20-34 and severe dependence by a score of 36-60. For the purposes of this paper, alcohol dependence was defined as a score of 4 or more on the SADQ. The reference period for the questions on alcohol dependence was the 6 months prior to interview.

\section{Drug dependence}

A number of questions designed to assess drug use were included in the questionnaire. Information was first obtained on all the types of drugs respondents had ever used, and then about the drugs used in the year before interview. Further information about drug use in the past year was collected for cannabis, amphetamines, crack, cocaine, ecstasy, tranquillisers, opiates and volatile substances (such as glue). This part of the survey included five questions to evaluate drug dependence, which was indicated by a positive response to any of them.

\section{Common mental disorders}

Non-psychotic psychiatric disorder was assessed using the Clinical Interview Schedule-Revised (CIS-R; Lewis et al, 1992). This can be administered by nonclinically trained interviewers, and training was straightforward for the experienced ONS interviewers employed for the survey. Moreover, the interview itself is relatively short (on average, $30 \mathrm{~min}$ ) compared with other methods of assessment. Common mental disorders were amalgamated into a single category, indicated by a total symptom score of 12 or over, assessed in relation to the previous week.

\section{Detection of psychosis}

A two-phase approach was adopted to assess the presence of psychotic disorder. The Psychosis Screening Questionnaire (Bebbington \& Nayani, 1995) was administered at the first interview. The criteria from this interview considered indicative of possible psychotic disorder were:

(a) self-report of symptoms suggesting psychotic disorder (e.g. hearing voices or mood swings) or of having been given a diagnosis of psychotic disorder;

(b) taking antipsychotic medication;

(c) a history of admission to a mental hospital or ward;

(d) a positive response to a question from the Psychosis Screening Questionnaire about auditory hallucinations.

Meeting any one of these criteria led to selection for a second-phase interview using version 2.1 of the Schedule for Assessment in Neuropsychiatry (World Health Organization, 1999). A proportion of people who screened negative were also selected for the second phase. Some of the people selected for a second-phase interview refused, however, and some could not be contacted during the fieldwork period. For this study we defined a group of interviewees as having 'definite or probable' psychotic disorder: 'definite' disorder was that identified by the SCAN, whereas 'probable' disorder was identified in those who had not had a SCAN interview but met two or more of the screening criteria described above. Endorsement of two or more items tallied closely with a positive diagnosis using SCAN in the Survey of Psychiatric Morbidity among Prisoners (Singleton et al, 1998). For brevity, these 60 respondents are described below as the 'psychosis group'.

\section{Selection and assessment of events}

All respondents were shown three cards listing stressful life events, and were asked to say which events, if any, they had experienced at any time of their life. The first card included relationship problems, illness and bereavement; the second, employment and financial crises; and the third, victimisation experiences. All the events were ones that might have had an adverse effect on the respondent's mental health. Here we have chosen to analyse the events that carried some connotation of victimisation: those listed on the third card, plus having experienced assault, injury or serious illness (Table 1). No attempt was made to evaluate the severity of the experiences. Finally, respondents were asked whether they had spent time in local authority care or in a children's institution before the age of 16 years.

\section{Analysis}

All analyses were performed using the relevant 'survey' commands in STATA 6.0 (StataCorp, 1999), which allow for the use of clustered data modified by probability weights and provide robust estimates of variance. We initially analysed the individual associations between events and disorders, after which we controlled for the association between events in their effects on the presence of psychosis by using logistic regression. Finally, we examined the effect of controlling for the level of depressed mood.

\section{RESULTS}

Overall, $10 \%$ of sampled addresses were ineligible because they contained no private households. Of the remaining addresses, $11 \%$ contained no one within the chosen age range, leaving an eligible sample of 12792 addresses. In the initial phase, just 
Table I Lifetime victimisation experiences by type of mental disorder: weighted percentages

\begin{tabular}{|c|c|c|c|c|c|c|}
\hline Lifetime & $\begin{array}{c}\text { Probable psychotic } \\
\text { disorder }(n=60)\end{array}$ & $\begin{array}{l}\text { Current neurotic } \\
\text { disorder }(n=1495)\end{array}$ & $\begin{array}{l}\text { Alcohol dependent } \\
\qquad(n=564)\end{array}$ & $\begin{array}{l}\text { Drug dependent } \\
\text { (any drug) }(n=256)\end{array}$ & $\begin{array}{l}\text { No disorder } \\
(n=6522)\end{array}$ & $\begin{array}{c}\text { Total } \\
(n=8520)^{\prime}\end{array}$ \\
\hline & $\%$ & $\%$ & $\%$ & $\%$ & $\%$ & $\%$ \\
\hline Sexual abuse & 34.5 & 11.8 & 4.2 & 6.0 & 1.8 & 3.5 \\
\hline Bullying & 46.4 & 29.7 & 23.3 & 28.9 & 14.6 & 17.4 \\
\hline Taken into local authority care & 17.9 & 4.6 & 3.7 & 3.9 & 1.6 & 2.2 \\
\hline Violence in the home & 38.1 & 19.5 & 11.9 & 19.8 & 4.1 & 7.0 \\
\hline Running away from home & 34.5 & 12.1 & 12.1 & 22.8 & 2.8 & 4.9 \\
\hline Time in a children's institution & 20.2 & 5.0 & 5.5 & 4.1 & 1.6 & 2.3 \\
\hline Being expelled from school & 1.2 & 3.6 & 5.6 & 12.1 & 0.9 & 1.6 \\
\hline Being homeless & 27.4 & 9.0 & 10.3 & I5.I & 2.1 & 3.6 \\
\hline Victim of serious injury, illness or assault & 64.3 & 39.9 & 35.7 & 30.2 & 22.9 & 26.2 \\
\hline
\end{tabular}

I. Because of comorbidity, base numbers do not sum.

Table 2 Lifetime victimisation experiences by type of mental disorder: odds ratios (ORs)

\begin{tabular}{|c|c|c|c|c|}
\hline Experience & $\begin{array}{c}\text { Probable psychotic } \\
\text { disorder } \\
\text { OR }(95 \% \mathrm{Cl})\end{array}$ & $\begin{array}{c}\text { Current neurotic } \\
\text { disorder } \\
\text { OR }(95 \% \mathrm{Cl})\end{array}$ & $\begin{array}{c}\text { Alcohol dependent } \\
\text { OR }(95 \% \mathrm{Cl})\end{array}$ & $\begin{array}{c}\text { Drug dependent } \\
\text { (any drug) } \\
\text { OR }(95 \% \mathrm{Cl})\end{array}$ \\
\hline Sexual abuse & $15.47(8.2-29.2)$ & $6.89(5.4-8.8)$ & $2.36(1.5-3.6)$ & $1.84(1.1-3.2)$ \\
\hline Bullying & $4.24(2.3-7.8)$ & $2.4 I(2.1-2.8)$ & $1.78(1.4-2.3)$ & $2.0 \mathrm{I}(1.5-2.7)$ \\
\hline Taken into local authority care & I0.7I (5.2-22.0) & $2.86(2.1-3.9)$ & $2.38(1.5-3.8)$ & $1.96(1.1-3.5)$ \\
\hline Violence in the home & $8.97(4.8-16.6)$ & $5.20(4.4-6.2)$ & $3.14(2.3-4.3)$ & $3.66(2.6-5.2)$ \\
\hline Running away from home & II.49 (6.2-2I.2) & $4.00(3.1-5.1)$ & $4.78(3.5-6.4)$ & $6.89(5.0-9.5)$ \\
\hline Time in a children's institution & II.87 (6.I-23.2) & $2.88(2.1-3.9)$ & $3.71(2.4-5.7)$ & $1.96(1.1-3.7)$ \\
\hline Being expelled from school & $0.88(0.1-6.3)$ & $3.32(2.3-4.9)$ & $6.91(4.3-11.2)$ & II.85 (7.4-18.9) \\
\hline Being homeless & II. $34(6.0-21.3)$ & $3.91(3.0-5.1)$ & $5.47(4.0-7.5)$ & $5.64(3.9-8.1)$ \\
\hline Victim of serious injury, illness or assault & $5.21(3.0-9.1)$ & $2.18(1.9-2.5)$ & $1.87(1.5-2.3)$ & I.24 (0.9-I.7) \\
\hline Violence at work & $3.66(1.4-9.5)$ & $1.77(1.3-2.3)$ & $2.82(I .9-4 . I)$ & $2.52(1.5-4.3)$ \\
\hline
\end{tabular}

I. Odds ratios comparison group comprises respondents with none of the four categories of disorder.

under $70 \%$ of those approached agreed to an interview. The vast majority of respondents $(95 \%)$ completed the full interview, despite its length. A total of 1036 respondents were selected for the second phase, of whom $874(84.4 \%)$ agreed to be interviewed and $638(61.6 \%)$ were interviewed successfully. The psychosis group comprised 27 persons assessed as having a psychotic disorder at the SCAN interview, and 33 who had not taken part in a SCAN interview but who reported at the initial interview two or more of the psychosis screening criteria. The overall prevalence of psychosis so defined was $0.7 \%$ (unweighted) and $0.5 \%$ (weighted).

In Table 1 we present the frequency of the various experiences in four case groups compared with respondents who were accorded no current diagnosis. For every experience, the prevalence was highest in the psychosis group, with the single exception of being expelled from school. These experiences were considerably less likely to be acknowledged by people who fell outside all the four case groups. We next provide the odds ratios for being in the different case groups, given a history of the various experiences (Table 2). This makes clear the increased risk of psychotic disorder in people with these experiences. The largest odds ratio was for sexual abuse, but it was followed closely by the experience of local authority care, residence in a children's institution, running away from home and being homeless.
Clearly, the odds ratios were very large. However, victimisation experiences may cluster in particular individuals, a relationship that might arise because of a clustering of disadvantage, because earlier events may predispose to later events, because early events interact with later events to increase the likelihood of psychosis or because of a reporting bias. It was therefore necessary to carry out a logistic regression in which the dependent variable was probable psychosis, and the experiences were entered together as independent variables. It is apparent from Table 3 that the reported events did indeed cluster in particular individuals: the significant odds ratios seen in Table 2 were much reduced. Although the largest odds ratio remained that associated 
with sexual abuse, some of the others were no longer significant (local authority care, bullying, violence at work) and the association with violence at home was only a non-significant trend. Childhood institutional care and local authority care overlap considerably, and it was unlikely that both would contribute significantly to the model. Controlling for the other experiences led to a significant inverse relationship with being expelled from school - i.e. people with psychosis are significantly less likely than the unaffected population to report having been expelled.

We repeated this analysis controlling for the key demographic variables of gender, age and ethnicity. We did not control for social class and educational attainment, as these are likely to be outcomes of the psychotic process. This analysis made remarkably little difference: the same event variables were required for the model of best fit. Finally, we took account of the possibility that the association of events with psychosis might better be explained by the effect of lowered mood. Lowered mood is common in psychosis, and the best-established links with events such as those we enquired about are with adult depression. We used the depression score on the CIS-R as a measure of lowered mood. As expected, this was strongly related to a study diagnosis of psychosis, to each of the victimisation events and to the experience of children's institutions and local authority care $(P<0.0001$ in every case).

Although controlling for depressed mood did reduce the odds ratios for the individual events and experiences, in no case was a significant association rendered non-significant. For example, the odds ratio of psychosis in the face of sexual abuse fell only from 15.5 to 7.4 . When we repeated the logistic analysis summarised in Table 3 with the additional entry of level of depressed mood, two circumstances ceased to contribute significantly to the model: being in a young persons' institution and being homeless. The effects of controlling for mood are shown in Tables 4 and 5 .

\section{DISCUSSION}

\section{Limitations of the study}

We chose to examine lifetime experience of certain events and situations likely to share at least some attributes of Harris's concept of intrusiveness (Harris, 1987). There are

Table 3 Logistic regression: relative odds of psychosis controlling for interrelationship between events

\begin{tabular}{lll}
\hline Experience & OR $(95 \% \mathrm{Cl})$ & $P$ \\
\hline Sexual abuse & $3.93(\mathrm{I} .8-8.6)$ & $0.00 \mathrm{I}$ \\
Bullying & $\mathrm{I} .62(0.8-3.4)$ & 0.20 \\
Taken into local authority care & $\mathrm{I} .08(0.6-2.1)$ & 0.82 \\
Violence in the home & $2.02(\mathrm{I} .0-4.3)$ & 0.07 \\
Running away from home & $2.86(\mathrm{I} .4-5.9)$ & 0.004 \\
Time in a children's institution & $2.11(\mathrm{I} .2-3.9)$ & 0.015 \\
Being expelled from school & $0.06(0.0-0.4)$ & 0.004 \\
Being homeless & $2.43(\mathrm{I} . \mathrm{I}-5.4)$ & 0.03 \\
Victim of serious injury, illness or assault & $3.22(\mathrm{I.9-5.6})$ & $0.00 \mathrm{I}$ \\
Violence at work & $\mathrm{I} .22(0.4-3.6)$ & 0.72 \\
\hline
\end{tabular}

Table 4 Psychotic disorder and individual victimisation events, controlling for current level of depression

\begin{tabular}{lll}
\hline Experience & OR $(95 \% \mathrm{Cl})$ & $P$ \\
\hline Sexual abuse & $7.4(3.6-15.2)$ & $0.000 \mathrm{I}$ \\
Bullying & $3 . \mathrm{I}(\mathrm{I} .6-5.9)$ & $0.00 \mathrm{I}$ \\
Taken into local authority care & $2.5(\mathrm{I} .7-3.7)$ & $0.000 \mathrm{I}$ \\
Violence in the home & $4.7(2.3-9.4)$ & $0.000 \mathrm{I}$ \\
Running away from home & $6.5(3.2-13.3)$ & $0.000 \mathrm{I}$ \\
Time in a children's institution & $2.5(\mathrm{I} .7-3.6)$ & $0.000 \mathrm{I}$ \\
Being expelled from school & $0.5(0.007-4.0)$ & 0.540 \\
Being homeless & $6.0(2.9-12.7)$ & $0.000 \mathrm{I}$ \\
Victim of serious injury, illness or assault & $3.7(2.1-6.7)$ & $0.000 \mathrm{I}$ \\
Violence at work & $2.7(\mathrm{I} .0-7.2)$ & 0.056
\end{tabular}

Table 5 Logistic regression: relative odds of psychosis controlling for interrelationship between events and for depression level

\begin{tabular}{lll}
\hline Experience & OR $(95 \% \mathrm{Cl})$ & $P$ \\
\hline Sexual abuse & $2.90(1.3-6.4)$ & 0.008 \\
Bullying & $1.42(0.7-3.1)$ & 0.37 \\
Taken into local authority care & $1.30(0.6-2.8)$ & 0.50 \\
Violence in the home & $1.43(0.7-3.1)$ & 0.36 \\
Running away from home & $2.80(1.3-5.9)$ & 0.007 \\
Time in a children's institution & $1.55(0.8-3.1)$ & 0.21 \\
Being expelled from school & $0.07(0.0-0.5)$ & 0.006 \\
Being homeless & $2.18(1.0-5.0)$ & 0.064 \\
Victim of serious injury, illness or assault & $2.9(1.7-5.0)$ & $0.00 \mathrm{I}$ \\
Violence at work & $1.17(0.4-3.9)$ & 0.79 \\
\hline
\end{tabular}

obvious difficulties in obtaining information of a potentially sensitive nature from individuals sampled in a national survey. It is, in any case, hard to validate such histories (collateral accounts, especially in relation to sexual abuse, can be difficult to obtain and are of dubious validity). People without psychiatric disorders may conceal, discount or fail to remember events, whereas those with disorders may seek explanations for their state in early experience. Thus there may 
be a differential bias in these reports. Reports from people who might have sexual delusions may be regarded with particular suspicion. Goodman et al (1997) examined the reliability of self-reports of violent victimisation among psychiatric patients with a range of disorders; they interviewed 50 patients on separate occasions 2 weeks apart and reported high levels of consistency in both men and women. They further compared the results with a prior study of reports of childhood abuse in college students (Goodman et al, 1997) and found similar reliability in both studies. However, these findings contrast with those reported by Fergusson et al (2000).

Reportage probably also depends on the format of enquiry. Dill et al (1991) found that psychiatric patients were twice as likely to acknowledge histories of physical or sexual abuse in childhood in a confidential self-report survey as at the routine intake interview, although nearly all the events recorded at intake were endorsed in the later enquiry. There might thus have been advantage in our procedure of presenting cards with the relevant experiences, as this might have been perceived by respondents as less intrusive than cross-questioning. Despite this, the endorsement of (for example) the experience of sexual abuse by our total sample was, at around $4 \%$, on the low side. We must ultimately acknowledge that validity remains insecure in studies such as this, and will be better dealt with through cohort studies.

There are other problems in interpreting our data. First, they relate to events occurring at an unspecified time in the respondents' lives. The timing of some of the individual experiences is constrained in the question (e.g. local authority care before age 16 years or being in a children's institution) and in other cases it can be inferred to some extent from their nature. Thus, being bullied is strongly a feature of school life, and even these days when bullying at work is more recognised, most respondents would imagine that the focus of the enquiry was the former. Running away from home is most likely to have occurred in adolescence. Violence in the home is quite likely to have been experienced in childhood, whereas violence at work would have occurred in adulthood. It might be expected that sexual abuse in people with psychiatric disorders is a childhood phenomenon (Friedman \& Harrison, 1984; Palmer et al, 1993, 1994), although some authors have suggested that exposure to sexual victimisation in psychiatric patients is more common in adulthood (Coverdale \& Turbott, 2000).

Ideally, we would have liked to explore the consequences of a model of psychosis in which early events contribute to vulnerability but the psychosis itself is triggered by later events. However, the timing of events was insufficiently demarcated to allow this.

\section{Confirmation of predictions}

Our first prediction was confirmed: all but one of the experiences we selected for analysis were reported significantly more frequently by the group of people with psychotic disorders than by those with no psychiatric problem. Our second prediction concerning the lack of specificity was also generally confirmed. People with common mental disorders, alcohol dependence or drug dependence also had high rates of reporting victimisation experiences. However, in each case the relative odds were highest in the psychosis group, with one interesting exception: a history of being expelled from school was not more frequent in the psychosis group than in the normal control group, whereas it was reported considerably more often in the alcohol-dependent group, and was particularly frequent in drug-dependent respondents. Being expelled involves the response of school authorities to unacceptable behaviour, usually of a flagrant kind. The distribution of expulsion between the groups of disorders suggests that the people with psychosis might have been socially reticent in adolescence, in contrast to the early acting-out behaviour of those with drug and alcohol misuse problems.

Some of the recorded experiences depended to a major extent on the actions of others (local authority care), whereas the contribution of respondents to other events is more central, for instance running away from home. Thus, we can infer no simple causal direction.

\section{Vulnerability to an increased event rate}

The results are also consistent with other possibilities, such as vulnerability to the unwelcome attention of others. This vulnerability may itself arise from prior social experience, or from attributes related to a genetic or other biological predisposition to psychosis. Goodman et al (1997) in their review paper found high rates of sexual victimisation in women with schizophrenia, including in adulthood. They did not postulate an effect of childhood abuse on schizophrenia, but rather concluded that the nature of the disorder left patients more vulnerable to abuse.

Given the cognitive and social deficits in some children who subsequently develop schizophrenia, they may be especially targeted by abusers because they are less likely to tell, are more easily intimidated or have greater difficulty in confiding in adults. Lysaker et al $(2001 a, b)$ found that self-reported childhood sexual abuse in people with schizophreniform disorders is linked to an increased severity of neurocognitive deficits and a reduction in psychosocial functioning. Done et al (1994) used a cohort study, the British National Child Development Study, to show that children who later developed schizophrenia had been rated as manifesting more social maladjustment at the age of 7 years than controls, especially in relation to overreactive behaviour. Bergman $e t$ al (1997) found that maltreated children had poorer neuromotor functioning and significantly more behaviour problems than non-maltreated children, regardless of parental psychiatric status. Put together, these studies suggest that maltreatment might influence the development of schizophrenia, but equally that behavioural oddities might lead both to maltreatment and to schizophrenia.

\section{Effect of shared genes}

Victimisation experiences may also cluster in individuals because of a spurious association brought about by the genetic relationship between parent and child. Child sexual abuse is associated with parental mental illness, with a two-to-three-fold increase in the offspring of parents who have schizophrenia compared with the general population (Walsh et al, 2002). However, most child sexual abuse is not perpetrated by the child's biological parents.

\section{Susceptibility to experiences}

A tendency to be victimised does not in itself reduce the impact on the individual experiencing victimisation, and the scene may then be set for a malignant spiral. Although the impact of sexual abuse in people who later develop depression may be mitigated by access to confiding adult relationships (Hill et al, 2001), such access 
may be less available to people with psychosis, and this in turn may increase their susceptibility to the impact of the events.

Some of the experiences covered by the rubrics used in our study are likely to be seriously traumatising, and raise the question of the relationship between psychosis and post-traumatic stress disorder (Bebbington \& Kuipers, 2003). Mueser et al (1998) found rates of $43 \%$ for posttraumatic stress disorder among 275 psychiatric patients with severe mental illness, the disorder being strongly predicted by multiple traumas and childhood sexual abuse. However, rates were lowest in schizophrenia and schizoaffective disorders.

\section{Other studies of early trauma in psychosis}

There are few studies of early sexual abuse in schizophrenia: they are small and methodologically limited. Friedman \& Harrison (1984) compared 20 women in-patients with schizophrenia with 15 controls recruited by anonymous questionnaires sent to female hospital employees. Sixty per cent of the patients acknowledged sexual abuse (i.e. rape or being fondled against their will) compared with $13.4 \%$ of controls. For most participants the abuse occurred in childhood, but no details are given. Nettelbladt et al (1996) reported significantly increased rates of 'sexual encroachment' (involving physical contact, a perpetrator and clear evidence of coercion) before age 18 years among 17 patients with schizoaffective disorder compared with controls. It remains possible that the experience of childhood sexual abuse is linked to adult psychosis because it is a marker for social poverty. Nelson et al (2002) have provided evidence that childhood sexual abuse is associated with a cluster of other adverse family factors.

\section{Mood as a mediator}

We considered whether the mediating factor might be depressed mood, and including this in the model did attenuate the relationships somewhat. Nevertheless, independent relationships between our chosen experiences and psychosis remained. Indeed, depressed mood is such a common correlate of schizophrenic symptoms that it is now hypothesised as being an important part of the process of their development (Birchwood \& Iqbal, 1998).

\section{CLINICAL IMPLICATIONS}

Psychosis may emerge especially in people who have been subjected to victimising events.

- Clinicians should seek to establish the existence and relevance of these experiences in their patients.

Cognitive-behavioural therapy for psychosis should continue to focus on the meaning of earlier traumas in relation to psychotic experiences.

\section{LIMITATIONS}

- The identification of psychosis was not wholly established by standardised clinical interview.

Events were not dated, although some were by definition early.

Reporting bias may account for some of the association between events and psychosis.

PAUL E. BEBBINGTON, PhD, FRCPsych, University College London Department of Psychiatry and Behavioural Sciences, Royal Free and University College Medical School; DINESH BHUGRA, PhD, FRCPsych, Institute of Psychiatry, London; TRAOLACH BRUGHA, PhD, MRCPsych, Department of Psychiatry, University of Leicester, Leicester; NICOLA SINGLETON, MSc, Office for National Statistics, London; MICHAEL FARRELL, MRCPsych, South London and Maudsley NHS Trust, RACHEL JENKINS, FRCPsych, WHO Collaborating Centre, Institute of Psychiatry, London; GLYN LEWIS, PhD, FRCPsych, Division of Psychiatry, University of Bristol, Bristol; HOWARD MELTZER, PhD, Office for National Statistics, London, UK

Correspondence: Professor Paul E. Bebbington, Department of Mental Health Sciences, 48 Riding House Street, London WIN 8EY,UK. Tel: +44 (0)207679 9465; e-mail: p.bebbington@ucl.ac.uk

(First received 21 August 2003, final revision 16 February 2004, accepted 9 March 2004)

\section{Significance of victimisation experiences}

There is marked clustering of experiences that can be generally described as victimising in people who are identified as probably having a psychotic disorder. These experiences are spread throughout the age span, but include those likely to have occurred during childhood, probably before the onset of the psychotic illness. We cannot rule out the possibility that they occurred in the context of early oddities of behaviour that might have been prodromal to the disorder. Nevertheless, the sheer burden of these experiences in people with psychosis is impressive, and at least suggests a process involving social influences. The research in this area is limited and should be augmented by work involving the more precise dating and characterisation of experiences. Ideally, this should include cohort studies.

\section{REFERENCES}

Bebbington, P. E. \& Kuipers, E. (2003) Schizophrenia and psychosocial stresses. In Schizophrenia (2nd edn) (eds S. R. Hirsch \& D.Weinberger), pp. 611-634. Oxford: Blackwell.

Bebbington, P. E. \& Nayani, T. (1995) The Psychosis Screening Questionnaire. International journal of Methods in Psychiatric Research, 5, II-20.

Bergman, A. J., Wolfson, M. A. \& Walker, E. F. (1997) Neuromotor functioning and behaviour problems in children at risk of psychopathology. Journal of Abnormal Child Psychology, 25, 229-237.

Birchwood, M. \& Iqbal, Z. (1998) Depression and suicidal thinking in psychosis: a cognitive approach. In Outcome and Innovations in Psychological Treatment of Schizophrenia (eds T.Wykes, N. Tarrier \& S. Lewis) pp. 8I-100. Chichester: John Wiley \& Sons.

Brugha, T. S., Nienhuis, F., Bagchi, D., et al (1999) The survey form of SCAN; the feasibility of using experienced lay survey interviewers to administer a semi-structured systematic clinical assessment of psychotic and non-psychotic disorders. Psychological Medicine, 29, 703-7II. 
Coverdale, J. H. \& Turbott, S. H. (2000) Sexual and physical abuse of chronically ill psychiatric outpatients compared with a matched sample of medical outpatients. Journal of Nervous and Mental Disease, $\mathbf{1 8 8}$ $440-445$.

Dill, D. L., Chu, J. A., Grob, M. C., et al (1991) The reliability of abuse history reports: a comparison of two inquiry formats. Comprehensive Psychiatry, 32, 166-169.

Done, J., Crow, T. J., Johnstone, E. C., et al (1994) Childhood antecedents of schizophrenia and affective illness: social adjustment at ages 7 and II. BMJ, 309, 699-703.

Fergusson, D. M., Horwood, L. J. \& Woodward, L. J. (2000) The stability of child abuse reports: a

longitudinal study of young adults. Psychological Medicine, 30, 529-544.

Friedman, S. \& Harrison, G. (1984) Sexual histories, attitudes and behaviour of schizophrenia and 'normal' women. Archives of Sexual Behaviour, 13, 555-567.

Garety, P., Kuipers, E., Fowler, D., et al (200I) Theoretical paper: a cognitive model of the positive symptoms of psychosis. Psychological Medicine, 31, $189-195$.

Goodman, L. A., Rosenberg, S. D., Mueser, K. T., et al (1997) Physical and sexual assault history in women with serious mental illness: prevalence, correlates, treatment, and future research directions. Schizophrenia Bulletin, 23, 685-696.

Harris, T. O. (1987) Recent developments in the study of life events in relation to psychiatric and physical disorders. In Psychiatric Epidemiology (ed. B. Cooper), pp. 8I-103. London: Croom Helm.
Hill, J., Pickles, A., Burnside, E., et al (200I) Child sexual abuse, poor parental care and adult depression: evidence for different mechanisms. British journal of Psychiatry, 179, 104-109.

Kish, L. (1965) Survey Sampling. London: Wiley

Lewis, G., Pelosi, A., Araya, R. C., et al (1992)

Measuring psychiatric disorder in the community: standardized assessment for use by lay interviewers. Psychological Medicine, 22, 465-486.

Lysaker, P. H., Meyer, P., Evans, J. D., et al (200la) Neurocognitive and symptom correlates of selfreported childhood sexual abuse in schizophrenia spectrum disorders. Annals of Clinical Psychiatry, I3, 89-92.

Lysaker, P. H., Meyer, P., Evans, J. D., et al (200Ib) Childhood sexual trauma and psychosocial functioning in adults with schizophrenia. Psychiatric Services, 52 1485-1488.

Mueser, K.T., Goodman, L. B., Trumbetta, S. L., et a (1998) Trauma and post-traumatic stress disorder in severe mental illness. Journal of Consulting and Clinical Psychology, 66, 493-499.

Nettelbladt, P., Svensson, C. \& Serin, U. (1996) Background factors in patients with schizoaffective disorder as compared with patients with diabetes and healthy individuals. European Archives of Psychiatry and Clinical Neuroscience, 246, 213-218.

Nelson, E. C., Heath, A. C., Madden, P. A. F., et al (2002) Association between self-reported childhood sexual abuse and adverse psychosocial outcomes: results from a twin study. Archives of General Psychiatry, 59, $139-145$.
Palmer, R. L., Coleman, L., Chaloner, D., et al (1993) Childhood sexual experiences with adults. A comparison of reports by women psychiatric patients and general-practice attenders. British Journal of Psychiatry, 163, 499-504.

Palmer, R. L., Bramble, D., Metcalfe, M., et al (1994) Childhood sexual experiences with adults: adult male psychiatric patients and general practice attenders. British Journal of Psychiatry, 165, 675-679.

Singleton, N., Meltzer, H., Gatward, R., et al (1998) Psychiatric Morbidity Among Prisoners in England and Wales. London: Stationery Office.

Singleton, N., Bumpstead, R., O'Brien, M., et al (200I) Psychiatric Morbidity Among Adults Living in Private Households, 2000. London: Stationery Office.

Stockwell, T., Murphy, D. \& Hogson, R. (1983) The severity of alcohol dependence questionnaire: its use, reliability and validity. British Journal of Addiction, $\mathbf{7 8}$, 145-155.

Walsh, C., MacMillan, H. \& Jamieson, E. (2002) The relationship between parental psychiatric disorder and child physical and sexual abuse: findings from the Ontario health supplement. Child Abuse and Neglect, 26 II-22.

World Health Organization (1992) The $I C D-10$ Classification of Mental and Behavioural Disorders: Clinical Descriptions and Diagnostic Guidelines. Geneva: WHO.

World Health Organization (1999) SCAN Schedules for Clinical Assessment in Neuropsychiatry Version 2.I. Geneva: WHO 